\title{
Alteration of Serotonin Release in the Guinea Pig Orbito-Frontal Cortex by Selective Serotonin Reuptake Inhibitors Relevance to Treatment of Obsessive-Compulsive Disorder
}

\author{
Mostafa El Mansari, Ph.D., Claude Bouchard, B.S., and Pierre Blier, M.D., Ph.D.
}

Potent serotonin (5-HT) reuptake inhibitors are the only antidepressant agents thus far shown to be effective in the treatment of obsessive-compulsive disorder (OCD). Positron emission tomography studies in humans have implicated the orbito-frontal cortex and the head of caudate nucleus in the mediation of OCD symptoms. Since the delay of the maximal therapeutic effect of selective 5-HT reuptake inhibitors (SSRI) is longer in OCD than in major depression and the terminal 5-HT autoreceptor is not desensitized in the guinea pig frontal cortex after 3 weeks of SSRI administration, the effects of the SSRI paroxetine $(10 \mathrm{mg} / \mathrm{kg} /$ day) and fluoxetine $(5$ $m g / \mathrm{kg} /$ day) on 5-HT release and on the sensitivity of the terminal 5-HT autoreceptor were investigated in the guinea pig frontal cortex, the orbito-frontal cortex, and the head of caudate nucleus following a washout period after 3 and 8 weeks of treatment. In preloaded slices prepared from guinea pigs treated with paroxetine for 3 weeks, the electrically evoked release of $\left[{ }^{3} \mathrm{H}\right] 5-\mathrm{HT}$ release was enhanced in the frontal cortex $(21 \%)$ but not in the orbito-frontal cortex or in the head of caudate nucleus. However, after an 8-week treatment, the evoked release of $\left[{ }^{3} \mathrm{H}\right] 5-H T$ was significantly enhanced in the orbito-frontal cortex $(55 \%)$ and in the rest of the frontal cortex $(29 \%)$ from the same animals, but still unchanged in the head of caudate nucleus. Concentration-effect curves, constructed with the 5-HT autoreceptor agonist 5-methoxytryptamine, showed that the terminal 5-HT autoreceptor was desensitized only in the orbito-frontal cortex after 8 weeks of treatment with paroxetine. Furthermore, the 5-HT transporter was desensitized in the frontal cortex but not in the orbito-frontal cortex. In the case of 3-or 8-week fluoxetine treatment, neither $\left.{ }^{3} \mathrm{H}\right] 5-H T$ release nor the sensitivity of the terminal 5-HT autoreceptor were altered in the orbito-frontal cortex and the head of caudate nucleus. This could be attributable to a smaller degree of 5-HT reuptake inhibition achieved with fluoxetine, in keeping with the notion that higher doses of SSRI are generally required to improve OCD than depression. Taken together, these results indicate that, in the orbito-frontal cortex, the enhanced release of $1^{3}$ HI5-HT induced by prolonged and marked 5-HT reuptake inhibition is attributable to a desensitization of the terminal 5-HT autoreceptor.

[Neuropsychopharmacology 13:117-127, 1995]
From the Department of Psychiatry, Neurobiological P'sychiatry Unit, McGill University, Montreal, Quebec, Canada.

Address correspondence to Professor Mostafa El Mansari, Department of Psychiatry, Neurobiological Unit, McGill University, 10133 Pine Avenue West, Montreal, Quebec, Canada H3A 1A1.

Received December 7. 1994; revised December 29. 1994; accepted February 13, 1995
KEY WORDS: Selective serotonin reuptake inhibitors; 1.H15-HT release; 5-HT autoreceptor; 5-HT transporter; Orbito-frontal cortex; Frontal cortex; Caudate nucleus; Obsessive-compulsive disorder 
Antidepressant drugs with potent inhibitory effects on serotonin (5-HT) reuptake, such as clomipramine, fluvoxamine, fluoxetine, and paroxetine, are thus far the only agents shown to be effective in the treatment of obsessive-compulsive disorder (OCD) (Fontaine and Chouinard 1985; Goodman et al. 1990; Insel et al. 1983; Steiner 1994). Since these selective 5-HT reuptake inhibitors (SSRI) belong to different chemical families and the only property they share is the capacity to potently block the 5-HT reuptake process, there is little doubt that they exert their therapeutic effects via the $5-\mathrm{HT}$ system. Two further lines of clinical evidence suggest that the 5-HT system is indeed involved in the therapeutic effect of SSRI in OCD. First, it has been reported that metachlorophenylpiperazine (MCPP), a drug with significant affinity for several 5 -HT receptor subtypes, can exacerbate OCD symptoms, possibly through a serotoninergic mechanism (Charney et al. 1988; Hollander et al. 1992; Zohar and Insel 1987). Second, administration of the 5-HT antagonist metergoline to patients with OCD who had improved with a 5-HT reuptake blocker produced a worsening of OCD and of anxiety symptoms (Benkelfat et al. 1989; Greenberg et al. 1994).

Considerable evidence already exists that the orbito-frontal cortex and the basal ganglia are involved in the symptomatology of OCD (Insel 1992). Indeed, provocative stimuli, which induced OCD symptoms, increased relative regional cerebral blood flow in the caudate nucleus, the orbito-frontal cortex, and the cingulate cortex (Rauch et al. 1994). Furthermore, treatment with clomipramine or fluoxetine leads to a reduction of activity in prefrontal areas, particularly the orbito-frontal cortex (Benkelfat et al 1990; Insel 1992; Swedo et al. 1992) and in the head of caudate nucleus (Baxter et al. 1987, 1992). It is striking that the reduction in orbito-frontal cortex and caudate activity has been associated with clinical improvement in OCD patients who responded either to pharmacotherapy or behavioral psychotherapy (Baxter et al. 1992).

Preclinical studies provide strong evidence that a variety of different antidepressant drugs potentiate 5-HT neurotransmission in the rat brain (Blier and do Montigny 1994). In the case of SSRI, this enhancement is attributable to cell body and terminal 5-HT autoreceptor desensitization. It was proposed that the enhanced 5-HT transmission occurring through 5-HT autorecep tor desensitization in certain brain regions (Blier and Bouchard 1994; Blier et al. 1988; Chaput et al. 198 n Chaput et al. 1991; Moret and Briley 1990b), such as the hippocampus and hypothalamus, might underlie at least in part, the therapeutic efficacy of SSRI in ma jor depression. It is striking, however, that this adap tive phenomenon does not occur in the frontal cortex despite the observation that 5-HT release was enhanced after a 3-week treatment with an SSRI (Blier and Bou chard 1994).

Given the longer delay for the maximal therapen tic effect of SSRI in OCD than in depression (Fineberg et al. 1992; Montgomery and Manceaux 1992), the important role of the frontal cortex in OCD (Insel 1992), and the lack of a desensitization of the terminal 5-HT autoreceptor in this structure after a 3-week SSRI treatment (Blier and Bouchard 1994), it was therefore deemed crucial to assess 5-HT release and the sensitivity of the terminal 5-HT autoreceptor in the orbito-frontal cortex and the caudate nucleus after a longer period of SSRI treatment ( 8 weeks). The experiments were carried out in guinea pigs because their terminal 5-HT autoreceptor are of the $5-\mathrm{HT}_{1 \mathrm{D}}$ subtype as in humans (Galzin et al. 1992; Hoyer and Middlemiss 1989; Maura et al. 1993).

\section{METHODS}

\section{Treatments}

Male guinea pigs (250-350 g) were anesthesized with halothane and implanted with an osmotic minipump (Alza, Palo Alto, CA, U.S.A.) that delivered the SSRI paroxetine (10 $\mathrm{mg} / \mathrm{kg} /$ day), fluoxetine $(5 \mathrm{mg} / \mathrm{kg} /$ day), or the vehicle used to dilute these two drugs (50/50 ethanol and water). For the 8 -week treatment, a new minipump was installed 4 weeks after the first implantation. After 3 or 8 weeks of treatment, the minipumps were removed under halothane anesthesia and the in vitro experiments were carried out 48 or 96 hours later to allow elimination of paroxetine or fluoxetine, respectively. The rationale for using these treatment regimens is the following. Previous studies had shown that 10 $\mathrm{mg} / \mathrm{kg} / \mathrm{day}$ of paroxetine produced a desensitization of the terminal 5-HT autoreceptor in the hypothalamus and the hippocampus after a 3-week treatment (Blier and Bouchard 1994). The $5-\mathrm{mg} / \mathrm{kg} /$ day regimen of fluoxetine was used because fluoxetine has an active metabolite, norfluoxetine, which is as potent and has a halflife about twice as long as that of the mother compound (Caccia et al. 1990). Consequently, a longer washout period was necessary for the fluoxetine than for the paroxetine treatment. For the $\left[{ }^{3} \mathrm{H}\right] 5-\mathrm{HT}$ uptake experiments, the guinea pigs were treated for 1 week with paroxetine or fluoxetine in order to achieve steady-state levels and were sacrificed with the minipump in place delivering the drug.

\section{Superfusion Experiments}

Guinea pigs were sacrificed by decapitation and the brain immediately removed and rapidly dissected on an ice-cold glass plate. Slices, $400 \mu \mathrm{m}$ thick, from the urbito-frontal cortex, the frontal cortex, and the head of caudate nucleus were prepared using a Mcllwain tissue chopper. The slices were then incubated with ['H]5-HT for 30 minutes at $37^{\circ} \mathrm{C}$ in Krebs buffer containing $20 \mathrm{nM}\left[{ }^{3} \mathrm{H}\right] 5-\mathrm{HT}$ creatinine sulfate (specific activity $1.1 \mathrm{~TB}^{\mathrm{m}} \mathrm{mmol}^{-1}$; NEN Research Products, Mis- 
sissauga, (anada) and bubbled with a mixture of $95 \%$ $\mathrm{O}_{2} / 5 \% \mathrm{CO}_{2}$. In order to prevent the uptake of $\left[{ }^{3} \mathrm{H}\right]$ 5-HT into dopaminergic nerve endings of caudate nucleus slices (Feuerstein et al. 1992), $1 \mu \mathrm{M}$ of nomifensine, a catecholamine uptake inhibitor, was added only for the incubation period. The composition of the Krebs' solution was the following (in $\mathrm{mM}$ ): $\mathrm{NaCl} 118, \mathrm{KCl} 4.7$, $\mathrm{CaCl}_{2} 1.3, \mathrm{MgCl}_{2} 1.2, \mathrm{NaH}_{2} \mathrm{PO}_{4} 1, \mathrm{NaHCO}_{3} 25$, glucose 11.1, $\mathrm{Na}_{2}$ EDTA 0.004, and ascorbic acid 0.11. At the end of the incubation period, the slices were washed and transferred to glass superfusion chambers (three slices of the head of caudate nucleus, two slices of orbitofrontal or frontal cortex) and superfused at a rate of 0.5 $\mathrm{ml} /$ minute with oxygenated Krebs' solution maintained at $37^{\circ} \mathrm{C}$. Nineteen consecutive 4 -minute fractions were collected starting 90 minutes after the beginning of superfusion for the three structures. Two periods of stimulation, $S_{1}$ and $S_{2}$, were carried out within the same experiment at 8 and 52 minutes, respectively, after the end of the 90-minute washing period. The electrical field was generated in the chambers between two platinum electrodes ( $30 \mathrm{~mA}, 2 \mathrm{~ms}, 3 \mathrm{~Hz}$ for 2 minutes), positioned $2 \mathrm{~cm}$ apart. The frequency of stimulation was chosen because it was within the range of the firing rate of 5-HT neurons recorded in freely moving cats (Jacobs 1986). The first stimulation period $\left(S_{1}\right)$ was used as control, and the drugs were added 20 minutes before $S_{2}$ and remained present throughout the rest of the experiment. At the end of superfusion period, the slices were solubilized with $0.5 \mathrm{ml}$ of Soluene 350 (Packard Instruments, Downers Grove, IL, L.S.A.), and the radioactivity in the slices and superfusate samples was determined by liquid scintillation spectrometry. The results were expressed as the fraction of the tritium content present in the time at the onset of the respective collection periods. The fractional release evoked by electrical stimulation was calculated as the difference between the to tal amount of radioactivity released during stimulation and the basal outflow obtained in the sample preced. ing the onset of stimulation (sp: or sp:). To assess the drug-induced changes of electrically evoked release of tritium from the slices preloaded with $\left[{ }^{3} \mathrm{H}\right] 5-\mathrm{HT}$, the ratio of fractional release between the second and the first period of stimulation ( $\left.S_{2} S_{1}\right)$ was calculated. The sp $2 \mathrm{sp}$. ratios were also calculated to determint whether the drugs altered the basal nutflow of radioa tivity. The amount of tritium released by electrical stim. ulation under these conditions provides a reliable estimate of the release of tritiated or endogenous 5-H (Baumann et al. 1981; Blier and Buchard 1993; Moret and Brilev 1490 a)

\section{Determination of $\left|{ }^{3} \mathrm{H}\right| 5-\mathrm{HT}$ Lptake}

Cortical slices were incubated in oxvgenated Krebs so lution at 37 ( to determon. in vitr. H/F.H uptahe
After a 3-minute period of stabilization, $\left[{ }^{3} \mathrm{H}\right] 5-\mathrm{HT}$ was added to the final concentration of $20 \mathrm{nM}$ in a total incubation volume of $2 \mathrm{ml}$. After 3 minutes of incubation, the uptake was stopped by transferring the slices into $5 \mathrm{ml}$ of ice-cold Krebs solution, they were then solubilized in $0.5 \mathrm{ml}$ of Soluene 350. A parallel experiment was carried out at $0^{\circ} \mathrm{C}$ as a control for passive diffusion. The radioactivity in the media and in the tissues was determined by liquid scintillation spectrometry. The inhibition of uptake was calculated according to the formula: \% inhibition of uptake $=\left(R_{\mathrm{C}}-R_{\mathrm{T}} / R_{\mathrm{C}}-R_{0}\right) \times$ 100 , where $R_{C}$ is the ratio of tissue to medium for the control slice, $R_{T}$ is the ratio of tissue to medium incubated with the drug, and $R_{0}$ is the ratio of tissue to medium for the control slice at $0^{\circ} \mathrm{C}$. The percentage inhibition was calculated by comparing the inhibition values obtained in the slices prepared from the control and treated guinea pigs.

Results are expressed as mean \pm SEM. Differences between the controls and the treated groups were compared by the two-tailed Student's $t$-test. In order to detect treatment effects, concentration-effect curves were constructed by studying simultaneously in the same superfusion apparatus slices prepared from a control and slices from a treated guinea pig with the same drug solution. The entire concentration-effect curves, rather than the means for each concentration, was compared using two-way analysis of variance. This experimental design was deemed optimal to minimize the problem of interexperimental variations. The following drugs were used: 5-methoxytryptamine (5-MeOT, Sigma, St. Louis, MO, U.S.A.), paroxetine (SmithKline Beecham, Harlow, England), fluoxetine (Eli Lilly and Company, Indianapolis, IN, U.S.A.), and nomifensine (Hoechst (anada Inc., Montreal, Canada).

\section{RESULTS}

\section{Effect of Paroxetine and Fluoxetine Administration on the Electrically Evoked Release of Tritium from $\left[{ }^{3} \mathrm{H}\right] 5-\mathrm{HT}$ Preloaded Slices}

The fractional release of tritium evoked by the first period of electrical stimulation $\left(S_{1}\right)$ was significantly enhanced 48 hours after a 3-week paroxetine treatment $110 \mathrm{mg} / \mathrm{kg}$ / day) in slices of the frontal cortex (21\%), but not in orbito-frontal or in the head of caudate slices of the same animals processed in parallel (Figure 1A). The spontaneous outflow of radioactivity in the sample immediately preceding this first period of stimulation (sp) was decreased in orbito-frontal cortex slices

$16 \%$ ) prepared from the 3-week paroxetine-treated zuinea pigs when compared to controls (Table 1). Afit $r$ an 8 -week treatment, the electrically evoked release if tritium in the absence of any drug in $S_{1}$ was significantly enhanced by $55 \%$ and $29 \%$ in orbito-frontal and trintal cortex slices, respectively, but still unchanged 
Table 1. Effect of Long-Term Administration of Paroxetine or Fluoxetine on the Spontaneous Outflow of Tritium from Guinea Pig Brain Slices Preloaded with $\left[{ }^{3} \mathrm{H}\right]$ 5-HT

\begin{tabular}{|c|c|c|c|c|c|c|c|c|}
\hline & \multicolumn{4}{|c|}{ Paroxetine } & \multicolumn{4}{|c|}{ Fluoxetine } \\
\hline & \multicolumn{2}{|c|}{ 3-Week Treatment } & \multicolumn{2}{|c|}{ 8-Week Treatment } & \multicolumn{2}{|c|}{ 3-Week Treatment } & \multicolumn{2}{|c|}{ 8-Week Treatment } \\
\hline & Control & Treated & Control & Treated & Control & Treated & Control & Treated \\
\hline Frontal cortex & $1.11 \pm 0.08$ & $\begin{array}{c}0.96 \pm 0.04 \\
(34)\end{array}$ & $0.88 \pm 0.03$ & $\begin{array}{c}0.89 \pm 0.04 \\
(31)\end{array}$ & - & - & - & - \\
\hline $\begin{array}{l}\text { Orbito-frontal } \\
\text { cortex }\end{array}$ & $0.93 \pm 0.05$ & $\frac{0.78 \pm 0.05^{\prime \prime}}{(28)}$ & $\begin{array}{c}0.78 \pm 0.03 \\
(38)\end{array}$ & $0.88 \pm 0.07$ & $\begin{array}{c}0.81 \pm 0.04 \\
(20)\end{array}$ & $\begin{array}{c}0.74 \pm 0.03 \\
(18)\end{array}$ & $0.85 \pm 0.03$ & $0.81 \pm 0.03$ \\
\hline $\begin{array}{l}\text { Head of caudate } \\
\text { nucleus }\end{array}$ & $\begin{array}{c}0.85 \pm 0.04 \\
(28)\end{array}$ & $\begin{array}{c}0.79 \pm 0.06 \\
(29)\end{array}$ & $0.87 \pm 0.05$ & $\begin{array}{c}0.97+0.05 \\
(19)\end{array}$ & $\begin{array}{c}0.83 \pm 0.04 \\
(17)\end{array}$ & $0.94 \pm 0.04$ & $\begin{array}{c}0.91 \pm 0.05 \\
(20)\end{array}$ & $\begin{array}{c}0.80 \pm 0.03 \\
(19)^{a}\end{array}$ \\
\hline
\end{tabular}

Each value represents the percentage of total tritium content present in the slices in the 4-minute sample of perfusate collected immediately before the first period of electrical stimulation. The numbers given in parentheses refer to the number of experiments.

" $p<.05$ when compared to the controls processed in parallel in the same experiments.

\section{A - PAROXETINE}

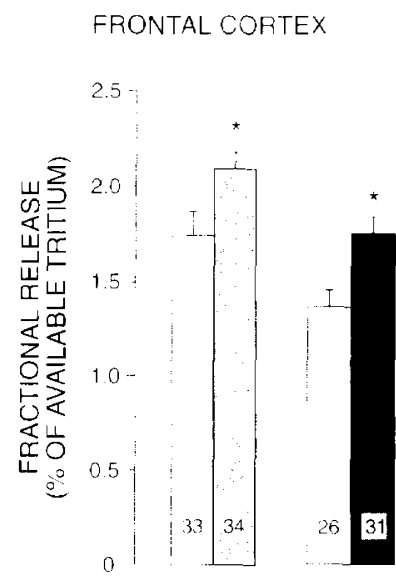

B - FLUOXETINE

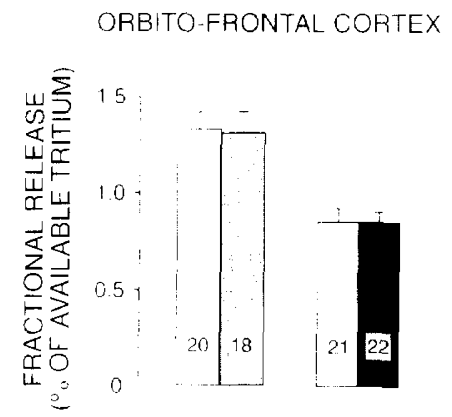

ORBITO-FRONTAL CORTEX

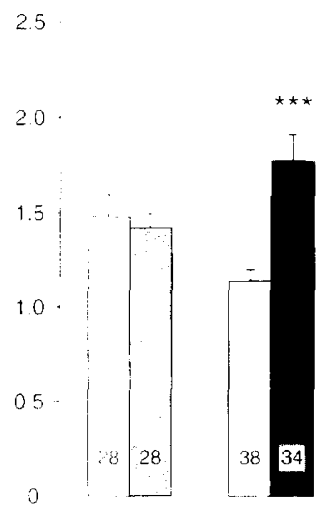

HEAD OF CAUDATE NUCLEUS

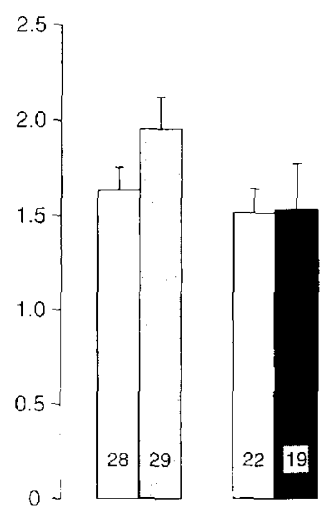

Figure 1. Effect of 3-week and 8-week paroxetine $(\mathbf{A})$ and fluoxetine $(\mathbf{B})$ treatment on the electrically stimulated tritium overflow in slices prepared from the orbito-frontal cortex, the frontal cortex, and the head of caudate nucleus and preloaded with $\left[{ }^{3} \mathrm{H}\right] 5-\mathrm{HT}$. Paroxetine and fluoxetine were administered using osmotic minipumps implanted subcutaneously and removed respectively 48 or 96 hours before sacrifice. Ordinate is the fraction of the total tissue radioactivity released by a 2-minute period of electrical stimulation $\left(S_{1}\right)(30 \mathrm{~mA}, 2 \mathrm{~ms}, 3 \mathrm{~Hz})$ applied 8 minutes after the end of the washout period. Experiments were carried out in pairs of guinea pigs, a control and a treated animal processed in parallel in the same perfusion apparatus. The number of experiments per group is given at the bottom of each column. Open bars: controls; shaded bars: 3-week treatment; solid bars: 8 -week treatment. 
in the slices of the head of caudate nucleus (Figure 1A). The spontaneous outflow of radioactivity $\left(\mathrm{sp}_{1}\right)$ was unaltered after an 8-week treatment (Table 1).

In the slices prepared from guinea pig treated with fluoxetine ( $5 \mathrm{mg} / \mathrm{kg} /$ day) for 3 and 8 weeks, the electrically evoked release of tritium was unaltered in the orbito-frontal cortex and the head of caudate nucleus slices, when compared to controls processed in parallel (Figure 1B). In slices of the head of caudate nucleus, the spontaneous outflow of radioactivity $\left(\mathrm{sp}_{1}\right)$ was significantly increased $(13 \%)$ after the 3-week treatment, but unchanged in orbito-frontal cortex slices after 3- and 8 -week treatments (Table 1). The total tissue content of radioactivity at the end of the experiments was not significantly altered in the slices prepared from guinea pigs treated with fluoxetine or paroxetine and in the controls (data not shown).

\section{Effect of Long-Term Paroxetine and Fluoxetine Treatment on the Modulation of Tritium Release by the Terminal 5-HT Autoreceptor from $\left[{ }^{3} \mathrm{H}\right] 5-\mathrm{HT}$ Preloaded Slices}

The sensitivity of the terminal 5-HT autoreceptor was investigated following 3 and 8 weeks of treatment with paroxetine or fluoxetine. Concentration-effect curves were constructed using slices of the orbito-frontal and the frontal cortex as well as of the head of caudate nucleus, in the presence of the 5-HT autoreceptor agonist 5-methoxytryptamine (5-MeOT). In frontal cortex slices prepared from guinea pigs treated for 3 weeks with paroxetine, there was a significant attenuation in the inhibitory effect of $0.1 \mu \mathrm{M} 5-\mathrm{MeOT}$ on the electrically evoked release of tritium. However, analysis of the concentration-effect curves did not indicate a statisti-

\section{A - 3 - WEEK PAROXETINE TREATMENT}

\section{FRONTAL CORTEX}

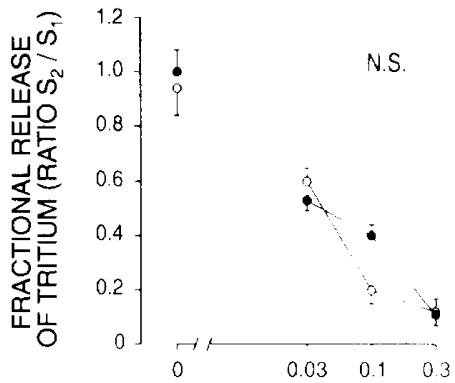

ORBITO-FRONTAL CORTEX

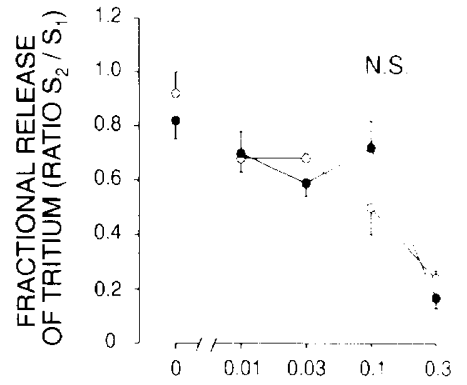

HEAD OF CAUDATE NUCLEUS

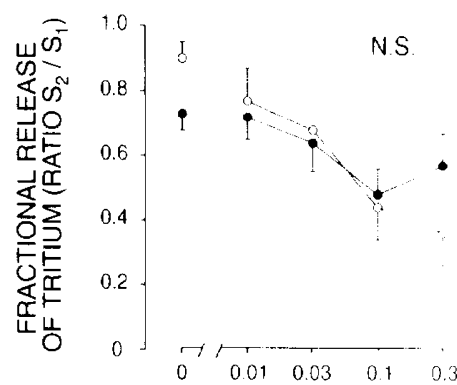

\section{B - 8 - WEEK PAROXETINE TREATMENT}
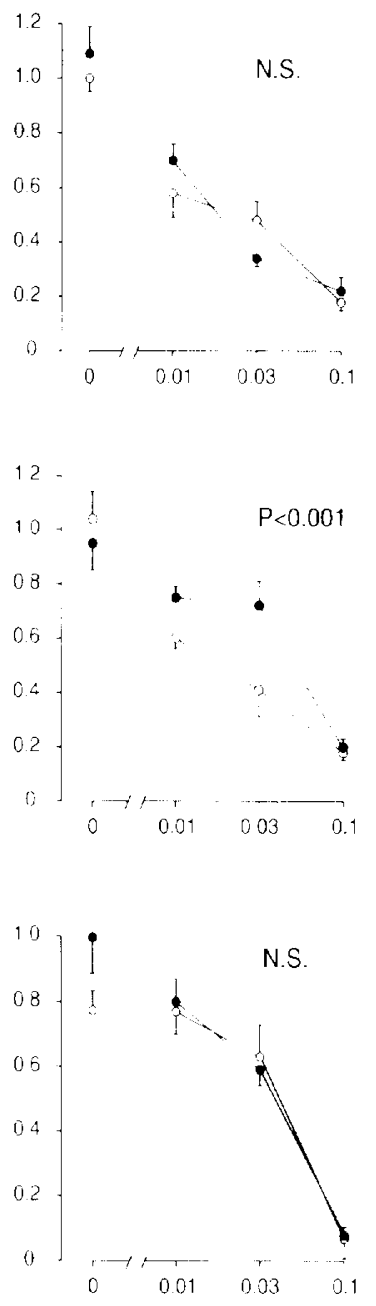

Figure 2. Concentration-effect curves of the 5-HT autoreceptor agonist 5-methoxy-tryptamine, introduced 20 minutes before $S_{2}$, on the release of tritium elicited by the electrical stimulation of orbito-frontal cortex, frontal cortex, and the head of caudate nucleus slices prepared from control (open symbols) and treated (filled symbols) guinea pigs with paroxetine for 3 weeks (A) or 8 weeks (B). Ordinate is the fraction of total tissue radioactivity released by 360 pulses ( $30 \mathrm{~mA}, 2 \mathrm{~ms}, 3 \mathrm{~Hz}$ for 2 minutes) expressed as the ratio $\left(S_{2} / S_{1}\right)$ obtained between the second period of stimulation in the presence of 5-methoxytryptamine $\left(S_{2}\right)$ and the first one done without this drug $\left(S_{1}\right)$. Each point represents the mean \pm SEM of at least five experiments per group in pairs of control and treated guinea pigs. The level of statistical significance, calculated using two-way analysis of variance between the curves obtained in the control and treated group is indicated in the graphs (NS: nonsignificant). 
A - 3 - WEEK FLUOXETINE TREATMENT

B - 8 - WEEK FLUOXETINE TREATMENT

ORBITO-FRONTAL CORTEX
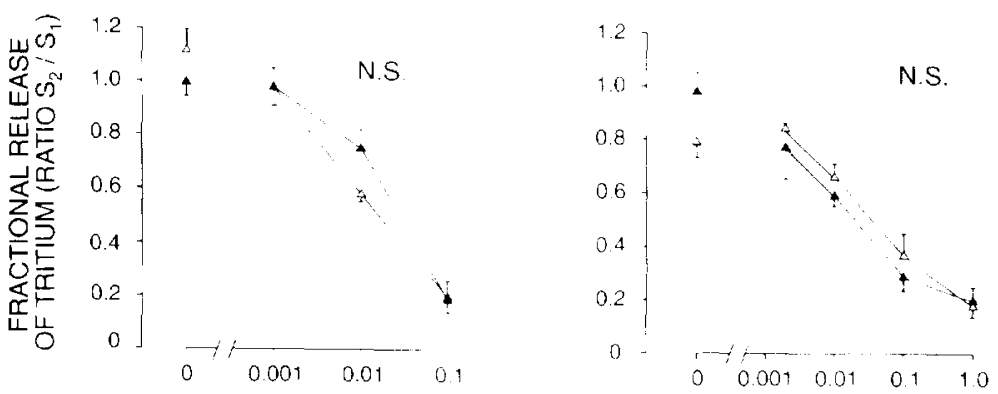

HEAD OF CAUDATE NUCLEUS
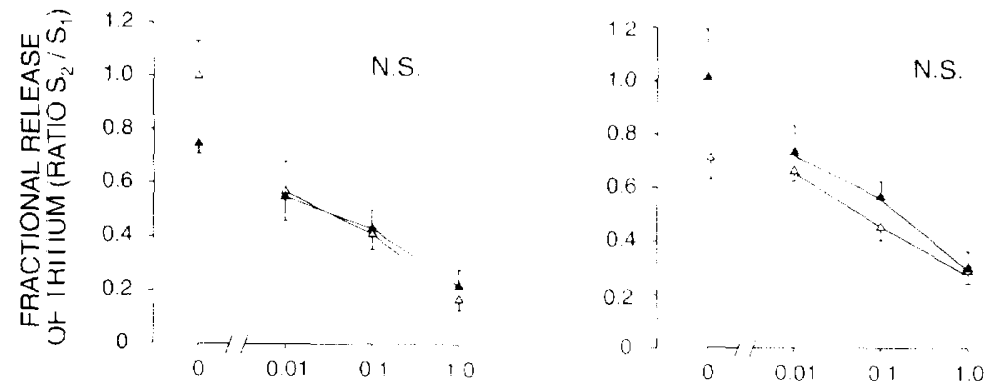

5-METHOXYTRYPTAMINE ( $\mu M)$

cally significant difference between the control and the paroxetine group (Figure 2A). Following a 3-week paroxetine treatment, the effectiveness of 5-MeOT in decreasing the evoked release of $\left[{ }^{3} \mathrm{H}\right] 5-\mathrm{HT}$ was unaltered in orbito-frontal cortex and the head of caudate nucleus slices (Figure 2A). After an 8-week treatment with paroxetine, however, there was a significant attenuation of the capacity of 5-MeOT to inhibit the electrically evoked release of tritium from preloaded orbitofrontal cortex slices, but not from frontal cortex and the head of caudate nucleus slices (Figure 2B).

Slices of the orbito-frontal cortex and the caudate nucleus of the 3-and 8-week fluoxetine-treated guinea pigs were also studied (Figures $3 \mathrm{~A}$ and $\mathrm{B}$ ). The concentration-effect curves in the 3 - and 8-week fluoxetine groups were similar to those of their matched controls in the two structures studied (Figures $3 \mathrm{~A}$ and $\mathrm{B}$ ).

\section{Effect of Acute and Chronic Paroxetine or Fluoxetine Administration on In Vitro [ $\left.{ }^{3} \mathrm{H}\right] 5-\mathrm{HT}$ Uptake and the Function of the 5-HT Transporter}

Lnexpectedly, the fluoxetine treatment $(5 \mathrm{mg} / \mathrm{kg} / \mathrm{day} \times$ 8 weeks) did not alter the function of 5 -HT terminals. In order to determine whether the differential effect of the fluoxetine and the paroxetine treatment was attributable to different degrees of 5-HT reuptake inhibition, $\left[{ }^{3} \mathrm{H}\right] 5$-HT uptake was determined in slices prepared from control and fluoxetine-or paroxetine-treated guinea pigs. A treatment period of 1 week was chosen in order to ensure that steady-state levels of fluoxetine and of norfluoxetine were achieved. In the fluoxetinetreated group, $\left[{ }^{3} \mathrm{H}\right] 5-\mathrm{HT}$ uptake was inhibited by $29 \%$ after a 1-week treatment (Figure 4A). However, following a 1-week treatment with paroxetine, $\left[{ }^{3} \mathrm{H}\right] 5-\mathrm{HT}$ uptake was inhibited by $56 \%$ in frontal cortex slices, with the minipump delivering the drug at the time of the sacrifice (Figure 4A), consistent with previous results obtained in our laboratory under identical conditions after 2 days of treatment with paroxetine (50\%; Blier and Bouchard 1994).

After a 48-hour washout, $\left[{ }^{3} \mathrm{H}\right] 5-\mathrm{HT}$ uptake in frontal cortex slices was not significantly inhibited in guinea pigs treated for 8 weeks with paroxetine $(18 \% \pm 6$, Figure 4B). However, following the 8-week fluoxetine treatment with a 96-hour washout, there was still a small but significant inhibition of the uptake of $\left[{ }^{3} \mathrm{H}\right] 5-\mathrm{HT}$ ( $23 \% \pm 7$, Figure $4 \mathrm{~B}$ ) following the 8-week fluoxetine treatment.

Paroxetine or fluoxetine was added to the superfusion medium to assess whether the 5-HT transporter had desensitized in slices prepared respectively from paroxetine- or fluoxetine-treated guinea pigs. In orbitofrontal cortex slices (Figure 5A), in presence of $1 \mu \mathrm{M}$ paroxetine introduced 20 minutes before $S_{2}$, the overflow of tritium was significantly increased following electrical stimulation in the vehicle group and also increased in the 8-week paroxetine group. An increase of tritium overflow was found in the presence of $1 \mu \mathrm{M}$ fluoxetine, introduced before $S_{2}$, in orbito-frontal cor- 
tex slices of the vehicle group and of the 8-week fluoxetine group (Figure 5A). In contrast, in frontal cortex slices (Figure $5 \mathrm{~B}$ ), the enhancing effect of $1 \mu \mathrm{M}$ paroxetine added before $S_{2}$ was present in the vehicle group but not in the 8-week paroxetine group.

\section{DISCUSSION}

The results of the present study indicate that following a 3-week treatment with the SSRI paroxetine $(10 \mathrm{mg}$; $\mathrm{kg}$ /day), $\left[{ }^{3} \mathrm{H}\right] 5-\mathrm{HT}$ release was enhanced in the frontal cortex but not in the orbito-frontal cortex or in the head of caudate nucleus. However, after an 8-week treatment, the release of 5-HT was significantly enhanced in the orbito-frontal cortex as well as in the rest of frontal cortex of the same animals, and still unchanged in the head of caudate nucleus. Concentrationeffect curves using the 5-HT autoreceptor agonist 5-MeOT, showed that the terminal 5-HT autoreceptor was desensitized only in the orbito-frontal cortex after 8 weeks of treatment with paroxetine, therefore putatively explaining, at least in part, the enhancement of 5-HT release in the latter brain region. In contrast, following 3-and 8-week treatments with fluoxetine (5 $\mathrm{mg}^{\prime} \mathrm{kg} /$ day), $\left.\left.\right|^{3} \mathrm{H}\right] 5-\mathrm{HT}$ release and the sensitivity of the terminal 5-HT autoreceptor remained unaltered in the head of caudate nucleus and orbito-frontal cortex

The lack of alteration of 5-HT release in orbitofrontal cortex and caudate nucleus after either 3 or $x$ weeks of fluoxetine treatment was most likely due to the absence of a modification of the sensitivity of the terminal 5-HT autoreceptor. This could be attributed to an insufficient dose of fluoxetine. This regimen was used because the half-life of fluoxetine and of its active metabolite norfluoxetine are relatively long in rodents (Caccia et al. 1990). Previous biochemical studies have shown that fluoxetine inhibits 5-HT reuptake in blood platelets (as indicated by marked depletion of $5-\mathrm{HT}$ ) within the same range, that is. 5 and $10 \mathrm{mg} / \mathrm{kg} /$ day administered orally in laboraturv animals (Schmidt et al. 1988). Although the dose of fluoxetine tested in this study is well within the range of those used in these previous studies, our results show that $\left[{ }^{3} \mathrm{H}\right] 5-\mathrm{HT}$ uptake was inhibited by only $29 \%$ after 1 week of fluoxetine administration in animals which were sacrificed with the minipump in place. This result and those obtained with paroxetine treatment indicate that both the dose and duration of a treatment with an SSRI are responsible for the development of 5-HT autoreceptor desensitization in the orbito-frontal cortex. Interest ingly, although little is currentl known about the relationship between effective anti-obsessional dose and blood level of 5-HT reuptake hlockers (Swedo et al. 1992), there is clinical evidence that higher doses of these antidepressant drug ma be required in treat
A - $\left[{ }^{\prime} \mathrm{H}\right] 5-\mathrm{HT}$ UPTAKE DURING TREATMENT

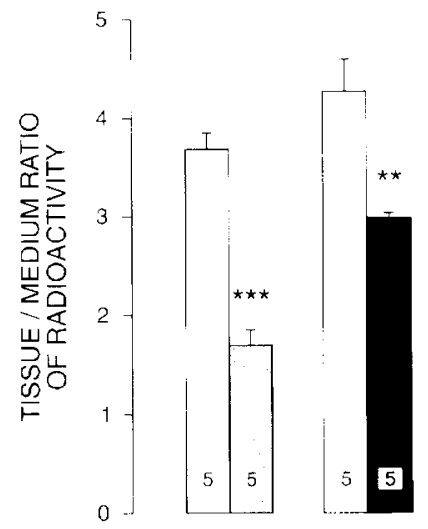

B - ['H]5-HT UPTAKE AFTER TREATMENT

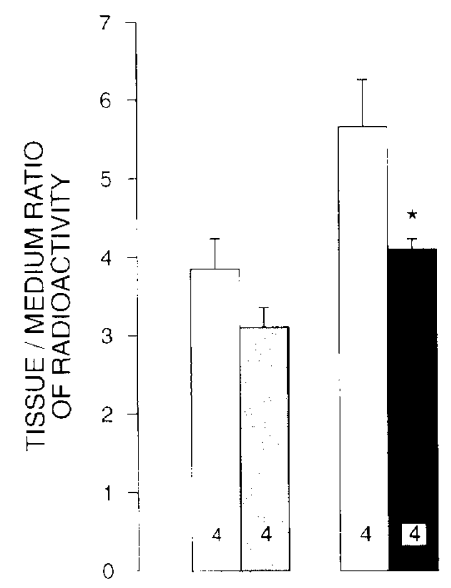

Figure 4. Inhibition of $\left[{ }^{3} \mathrm{H}\right] 5-\mathrm{HT}$ uptake in the frontal cortex of guinea pig following a paroxetine or fluoxetine treatment with the minipump delivering the drug at the time of sacrifice after 1 week of treatment (A) or after 8 weeks of treatment with washout (B), 48 hours in the case of the paroxetine treatment, and 96 hours for fluoxetine. Inhibition of $\left[{ }^{3} \mathrm{H}\right] 5-\mathrm{HT}$ uptake was determined by incubating the slices with $20 \mathrm{nM}$ [ $\left.{ }^{3} \mathrm{H}\right] 5-\mathrm{HT}$ for 3 minutes. The percentage of inhibition was calculated by comparing the tissue/medium ratios of radioactivity in the control and the treated groups. The number of experiments per group is given at the bottom of each column. ${ }^{\star} p<.05 ;{ }^{\star \star} p<.01 ;{ }^{\star \star \star} p<.001$ when compared to the tissue-medium ratios obtained in the controls processed in parallel in the same experiments. Open bars: control; shaded bars: paroxetine; solid bars: fluoxetine.

ing OCD than depression (Chouinard 1992; Montgomery et al. 1993).

Following an 8-week but not a 3-week paroxetine treatment, $\left[{ }^{3} \mathrm{H}\right] 5-\mathrm{HT}$ release was significantly enhanced in the orbito-frontal cortex than in the rest of the frontal cortex, presumably because of a desensitization of the terminal 5-HT autoreceptor. Consistent with the latter assumption were the observations that, after a 3-week paroxetine treatment, the sensitivity of 
A - ORBITO-FRONTAL CORTEX

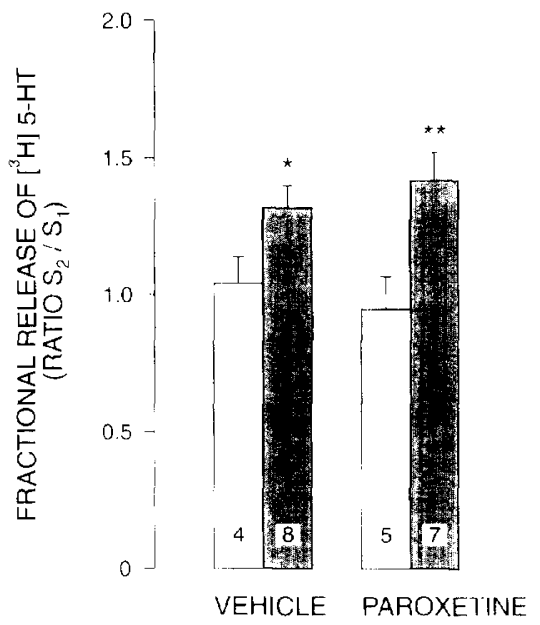

B - FRONTAL CORTEX

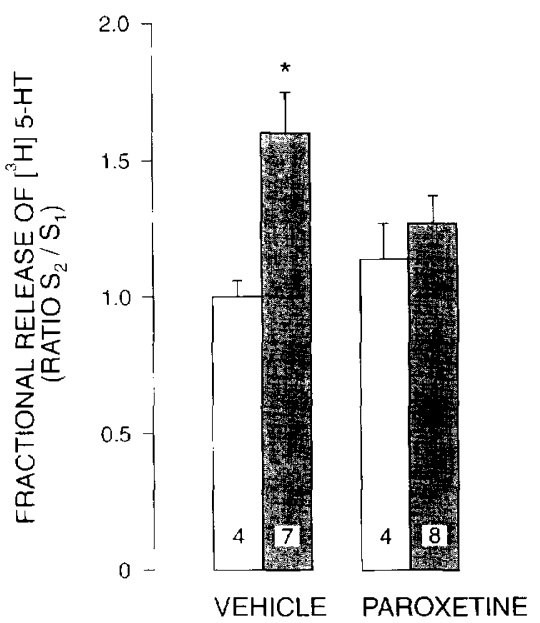

Figure 5. Effect of paroxetine or fluoxetine $(1 \mu \mathrm{M})$, introduced 20 minutes before $S_{2}$, on the electrically evoked release of tritium from orbito-frontal cortex slices preloaded with $\left[{ }^{3} \mathrm{H}\right] 5-\mathrm{HT}$ in (A) and frontal cortex in (B), prepared from control and treated guinea pigs, respectively, with paroxetine or fluoxetine for 8 weeks. Ordinate is the fraction of the total tissue radioactivity released by 2-minute periods of electrical stimulation expressed as the ratio $\left(S_{2} / S_{1}\right)$ obtained between the second period of stimulation in the presence of drug $\left(S_{2}\right)$ and the first one done without this drug $\left(S_{1}\right)$. The number of experiments per group is given at the bottom of each column. ${ }^{\star} p<.05 ;{ }^{*} p<.01$ when compared to the tissue/medium ratios obtained in the controls processed in parallel in the same experiments. Open bars: controls; shaded bars: paroxetine (1 $\mu \mathrm{M})$ before $S_{2}$; filled bars: fluoxetine $(1 \mu \mathrm{M})$ before $S_{2}$.

the terminal 5-HT autoreceptor was not altered in the orbito-frontal cortex and $\left[{ }^{3} \mathrm{H}\right] 5-\mathrm{HT}$ release was not enhanced. That this change in $\left[{ }^{3} \mathrm{H}\right] 5-\mathrm{HT}$ release in the orbito-frontal cortex might be due to 5 -HT reuptake blockade per se can be excluded, since experiments were performed 48 hours after the removal of minipump to allow elimination of the drug. Indeed, $\left[{ }^{3} \mathrm{H}\right]$ 5-HT uptake was not significantly altered in 8-week paroxetine-treated animals after a 48 -hour washout (Figure 4B). The possibility that the decreased function of the terminal 5-HT autoreceptor in orbito-frontal cortex following the 8-week paroxetine treatment also resulted from a desensitization of 5-HT transporter can be ruled out by the ability of $1 \mu \mathrm{M}$ paroxetine, introduced 20 minutes before $S_{2}$, to significantly enhance the evoked release of $\left[{ }^{3} \mathrm{H}\right] 5-\mathrm{HT}$ in the superfusion medium. The sustained increase in extracellular availability of 5-HT, as a result of 5-HT reuptake blockade after an 8-week paroxetine treatment, is unlikely to be responsible for 5-HT autoreceptor desensitization since monoamine oxidase inhibitors, which have been shown to increase 5-HT release, do not reduce the function of the terminal 5-HT autoreceptor (Blier et al. 1986, 1988). Taken together, these results indicate that the enhanced release of $\left[{ }^{3} \mathrm{H}\right] 5$-HT induced by an 8 -week 5 -HT reuptake inhibition is entirely attributable to a desensitization of the terminal 5-HT autoreceptor in the orbito-frontal cortex.

It has been shown that the modulation of 5-HT release from 5-HT terminals by their terminal autorecep- tors presents the characteristics of $5-\mathrm{HT}_{1 \mathrm{~B}}$ receptors in rats (Engel et al. 1986). In the human brain, the terminal autoreceptor is of the 5-HT 1 D subtype (Galzin et al. 1992; Maura et al. 1993) and therefore guinea pigs were used in the present study since their terminal 5-HT autoreceptors are also of the 5-HT ${ }_{1 D}$ subtype (Hoyer and Middlemiss 1989; Limberger et al. 1991). Recently, we have shown that the terminal 5-HT autoreceptor in the guinea pig hypothalamus and the hippocampus are desensitized after a 3-week paroxetine treatment (Blier and Bouchard 1994). However, these results stand in contrast with the present data showing a desensitization of terminal 5-HT autoreceptor in the orbito-frontal cortex occurring only after an 8-week paroxetine treatment. Since the conditions used in this in vitro study were the same as those used in these previous experiments, with the exception of the longer duration of treatment, it is thus conceivable that the difference in the time constant of autoreceptor desensitization in the hypothalamus/hippocampus versus the orbito-frontal cortex reflects (if the autoreceptor is the same) different mechanisms modulating the function of this receptor. Therefore, the differential effects of paroxetine on the sensitivity of the terminal 5-HT autoreceptor in these different regions could possibly be explained by different signal transducing systems mediating the effect of the terminal 5-HT autoreceptor on 5-HT release. For instance, it has been demonstrated that the negative coupling of the $5-\mathrm{HT}_{1 \mathrm{D}}$ binding sites to an adenylyl cyclase is present in the substantia nigra but not in the stria- 
tum (Waeber et al. 1989). Experiments are under way in our laboratory to investigate this issue.

In the case of the frontal cortex, the lack of 5-HT autoreceptor desensitization after either 3 or 8 weeks of paroxetine treatment, suggests that the enhanced release of 5-HT could be attributable to changes in the function of the 5-HT transporter. Yet, in the 3-week paroxetine-treated group, based on the acute effect of paroxetine, it was suggested that the enhanced release of $\left[{ }^{3} \mathrm{H}\right] 5-\mathrm{HT}$ in guinea pig frontal cortex could be derived from a decrease in the number of $5-\mathrm{HT}$ carriers (Blier and Bouchard 1994). Indeed, it has been reported that the $B_{\max }$ value for 5-HT transporters in the rat frontal cortex is decreased following 3 weeks of paroxetine administered via an osmotic minipump (Piñeyro et al. 1994). Our results obtained in guinea pigs treated with paroxetine for 8 weeks showed the same degree of increase of $\left[{ }^{3} \mathrm{H}\right] 5-\mathrm{HT}$ release in the frontal cortex and thus support the assumption that this enhanced release resulted from a downregulation of the $5-\mathrm{HT}$ transporter Moreover, the fact that 5-HT transporters are desensitized in frontal but not orbito-frontal cortex after an 8-week paroxetine treatment suggests that they are endowed with different properties. Here again, the regional differences in the adaptability of 5-HT transporters could be explained on the basis of differences in transducing mechanisms or distinct subtypes of 5-HT transporters. This latter possibility is compatible with the detection of multiple messenger RNA species encoding the 5-HT transporter in humans (Austin et al. 1993; Ramamoorthy et al. 1993).

The observation of the reappearance of depressive symptoms observed after acute tryptophan depletion in patients successfully treated with SSRI suggests that the antidepressant response is due to increased 5-HT neurotransmission following SSRI administration (Delgado et al. 1990). In contrast, the same depletion did not change mean ratings of obsessions and compulsions in OCD patients successfully treated with SSRI, thus indicating distinct mechanisms of action of the SSRI in OCD and major depression. This difference may well stem from the differential effect of SSRI in brain regions implicated in depression and OCD. It is possible that a prolonged tryptophan depletion with provocative stimuli could induce a relapse of obsessive-compulsive symptoms in patients treated with SSRI. Another approach to demonstrate the implication of the 5-HT system in the therapeutic effect of SSRI in OCD would be to interrupt the SSRI treatment before carrying out the 2-day tryptophan depletion. This strategy might be more likely to produce a relapse since it was observed in the present study that the 5-HT transporter is not desensitized in the orbito-frontal cortex following paroxetine treatment.

The close association between orbito-frontal cortex metabolic activity and plasma level of clomipramine leads one to believe that a possible site of action of this drug might be the orbito-frontal region (Swedo et al. 1992). However, in spite of the rapid onset of the inhibition of 5-HT reuptake in humans by SSRI, their maximal therapeutic improvement is generally achieved only after 6 to 8 weeks in depression and only after 10 to 12 weeks in OCD (Goodman et al. 1989; Montgomery and Manceaux 1992). Interestingly, the present results show an increase of $\left[{ }^{3} \mathrm{H}\right] 5$-HT release in the orbitofrontal cortex after an 8-week, but not a 3-week, paroxetine treatment. Thus, the time course of the occurrence of this adaptive change in the orbito-frontal cortex is congruent with the delayed therapeutic response to SSRI in OCD.

An important result in this study was the unaltered $\left[{ }^{3} \mathrm{H}\right] 5-\mathrm{HT}$ release after an 8-week paroxetine administration in the head of caudate nucleus, which is also involved in OCD symptoms. Fluoxetine has been found to decrease metabolic activity in frontal cortex but not in the caudate nucleus (Hoehn-Saric et al. 1991), thus suggesting that factors not associated with 5-HT neurotransmission underlie the metabolic alteration in the caudate nucleus of OCD patients (Hoehn-Saric and Benkelfat 1994). This is concordant with generally less consistent changes found with positron emission tomography in the head of caudate nucleus observed in baseline scans, during symptoms provocation, or during treatment (Baxter et al. 1987, 1988, 1992; Benkelfat et al. 1990; Rauch et al. 1994). Taking into consideration that the caudate nucleus and the orbito-frontal cortex are components of basal ganglia-thalamo-cortical circuitry, which is implicated in the pathophysiology of OCD (Alexander et al. 1989; Wise and Rapoport 1989), the treatment-induced enhancement of $\left[{ }^{3} \mathrm{H}\right] 5-\mathrm{HT}$ release in the orbito-frontal cortex should have consequences on the other structures of this circuitry.

In closing, one must bear in mind that it is not only alterations of the presynaptic components that can underlie the effectiveness of a drug treatment, but also the responsiveness of postsynaptic 5-HT receptors in investigating overall 5-HT neurotransmission. Experiments are presently under way in our laboratory to study eventual changes in the function of postsynaptic 5 -HT receptors mediating the effect of 5-HT in brain structures involved in OCD.

\section{ACKNOWLEDGMENTS}

This study was supported by the Medical Research Council of Canada (grant MA-11014 and scholarship) to Pierre Blier and the Fonds de la Recherche en Santé du Québec (FRSQ). Mostafa El Mansari received postdoctoral fellowships from the FRSQ and the Royal Victoria Hospital Research Institute. We would like to thank $T$. Vo for his help with computer analyses and $\mathrm{H}$. Cameron for secretarial assistance. 


\section{REFERENCES}

Alexander GE, DeLong MR, Strick PL (1989): Parallel organization of functionally segregated circuits linking basal ganglia and cortex. Ann Rev Neurosci 9:357-381

Austin MC, Bradley C(, Mann J]. Arango V, Blakely RD (1993): Localization of serotonin transporter messenger RNA in the human brainstem. Soc Neurosci Abst 22:4

Baumann PA, Waldmeier PC (1981): Further evidence for negative feedback control of serotonin release in the central nervous system. Naunyn-Schmiedeberg's Arch Pharmacol 317:36-43

Baxter LR Jr, Phelps JM, Mazziotta IC, Guze BH, Schwartz. JM (1987): Local cerebral glucose metabolic rates in obsessive-compulsive disorder: A comparison with rates in unipolar depression and normal controls. Arch Gen Psychiatry 44:211-218

Baxter LR Jr, Schwartz. IM, Bergman KS, Szuba MP, Guze BH, Mazziotta JC, Alazraki A, Selin CE, Ferng H-K, Munford P, Phelps ME (1992): Caudate glucose metabolic rate changes with both drug and behavioral therapy for obsessive-compulsive disorder. Arch Gen Psychiatrv 49:681-689

Baxter LR Jr, Schwart/ JM, Maz_iotta IC, Phelps ME, Pahl J], Guze BH, Faifbanks L. (1988): (erebral glucose metabolic rates in non-depressed patients with obsessivecompulsive disorder. Am ] ['svchiatry 145:1560-1563

Benkelfat C, Murphy DL. Zohar I, Hill IL, Grover G, Insel TR (1989): Clomipramine in obsessive-compulsive disorder: further evidence for a serotonergic mechanism of action. Arch Gen Psvchiatru 46:23-28

Benkelfat C, Nordahl TE, Semple WE, King C, Murphy DI. Cohen RM (1990): Local ieretoral glucose metabolic rates in obsessive-compulsive disorder: Patients treated with clomipramine. Arch Gen Psychiatry 47:840-848

Blier P, Bouchard C (1993): Functional characterization of a $5-\mathrm{HT}_{3}$ receptor which modulates the release of $5-\mathrm{HT}$ in the guinea pig brain. Br I Pharmacol 108:13-22

Blier P, Bouchard C (1994): Mudulation of 5-1 HT release in the guinea pig brain following long-term administration of antidepressant drugs. Br I Jharmacol 113:485-495

Blier P, Chaput Y, de Montignt ( (1988): Long-term 5-HT reuptake blockadt, but not monoamine oxidase inhibi tion, decreases the function of the terminal 5-HT au toreceptors: An electrophysiological study in the rat brain. Naunyn-Schmiedeberg's Arch Pharmacol 337 246-254

Blier P, de Montigny ( 1 1494: Current advances and trend in the treatment of depresision. Trends Pharmacol $S_{0}$ $15: 220-226$

Blier P, de Montigny (. A/Aare Al (1986): Modification of serotonergic and nuradrenergic neurotransmission by repeated administration of monoamine oxidase inhibi tors: Electrophysiolognal studies in the rat. I I'harmacol Exp Ther 227:987 494

Caccia S, Cappi M, Fracason C. Garattini S (1990) Influenu of dose and route of administration on the kinetics at fluoxetine and its metabolite norfluoxetine in the rat I'st chopharmacology $100: 5(19-514$

Chaput Y, de Montigns ( Blier P (1986): Effects of a seles tive 5-HT reuptake blocker, citalopram, on the sensitic ity of 5-HT autoreceptors: Electrophysiological studies in the rat. Naunyn-Schmiedeberg's Arch Pharmacol 33:342-349

Chaput $Y$, de Montigny C, Blier P (1991): Presynaptic and postsynaptic modifications of the serotonin system by long-term administration of antidepressant treatments: An in vivo electrophysiologic study in the rat. Neuropsychopharmacology 5:219-229

Charney DS, Goodman WK, Price LH, Woods SW, Rasmussen SA, Heninger GR (1988): Serotonin function in obsessive-compulsive disorder. A comparison of the effects of tryptophan and $\mathrm{m}$-chlorophenylpiperazine in patients and healthy subjects. Arch Gen Psychiatry: $45: 177-185$

Chouinard G (1992): Sertraline in the treatment of obsessivecompulsive disorders: Two double-blind, placebo-controlled studies. Int Clin Psychopharmacol 7:37-41

Delgado PL, Charney DS, Price LH, Aghajanian GK, Landis H. Heninger GR (1990): Serotonin function and the mechanism of antidepressant action: Reversal of antidepressant-induced remission by rapid depletion of plasma tryptophan. Arch Gen Psychiatry 47:411-418

Engel G, Gothert M, Hoyer D, Schlicker E, Hillenbrand K (1986): Identity of inhibitory presynaptic 5-hydroxytryptamine (5-HT) autoreceptors in the rat brain cortex with 5-HT $1 \mathrm{~B}$ binding sites. Naunyn-Schmiedeberg's Arch Pharmacol 332:1-7

Feuerstein TJ, Lupp A, Hertting G (1992): Quantitative evaluation of the autoinhibitory feedback of release of 5-HT in the caudate nucleus of the rabbit where an endogenous tone on $\alpha_{2}$-adrenoceptors does not exist. Neuropharmacology 31:15-23

Fineberg NA, Bullock T, Montgomery DB, Montgomery SA (1992): Serotonin reuptake inhibitors are the treatment of choice in obsessive-compulsive disorder. Int Clin Psychopharmacology 7(Suppl 1):43-47

Fontaine R, Chouinard G (1985): Fluoxetine in the treatment of obsessive-compulsive disorder. Prog Neuropsychopharmacul Biol Psychiatry 9:605-608

Galzin AM, Poirier MF, Lista A, Chodkiewicz JP, Blier P, Ramdine R, Loo H, Roux FX, Redondo A, Langer SZ (1992): Characterization of the 5-hydroxytryptamine receptor modulating the release of $5-\left[{ }^{3} \mathrm{H}\right]$ hydroxytryptamine in slices of the human neocortex. J Neurochem 59:1293-1301

Gordman WK, Price LH, Delgado PL, Palumbo J, Krystal JH, Vagy LM, Rasmussen SA, Heninger GR, Charney DS (1990): Specificity of serotonin reuptake inhibitors in the treatment of obsessive-compulsive disorder. Comparison of fluvoxamine and desipramine. Arch Gen Psychiatry 47:577-585

Goodman WK, Price LH, Rasmussen SA, Delgado PL, Heninger GR, Charney DS (1989): Efficacy of fluvoxamine in obsessive-compulsive disorder: A double-blind comparison with placebo. Arch Gen Psychiatry 46:36-44

Creenberg B, Benjamin J, Murphy D (1994): Metergoline biphasically enhances, then antagonizes, fluoxetine's therapeutic effects in obsessive-compulsive disorder. Veuropsychopharmacology 10:256S

H wehn-Saric R, Benkelfat C (1994): Structural and functional brain imaging in OCD. In Hollander E, Zohar J, Marazzati $D$, and Olivier B (eds), Current concepts in Obsessive Compulsive Disorder. New York, Wiley, pp 183-211 
Hoehn-Saric R, Pearlson (;D, Harris G], Machlin SR, Camargo EE (1991): Effects of fluoxetine on regional cerebral blood flow in obsessive-compulsive patients. Am J Psychiatry $148: 1243-1245$

Hollander E, DeCaria CM, Nitescu A, Gully R, Suckow RF, Cooper TB, Gorman JM, Klein DF, Liebowitz MR (1992): Serotonergic function in obsessive-compulsive disorder. Behavioral and neuroendocrine responses to oral $m$-chlorophenylpiperazine and fenfluramine in patients and healthy volunteers. Arch Gen P'sychiatry 49:21-28

Hoyer D, Middlemiss DN (1989): Species differences in the pharmacology of terminal 5-HT autoreceptor in mam malian brain. Trends Pharmacol Sci 10:130-132

Insel TR (1992): Toward a neuroanatomy of obsessivecompulsive disorder. Arch Gen Psychiatry 49:739-744

Insel TR, Murphy DL, Cohen RM, Alterman I, Kilts C, Linnoila M (1983): Obsessive compulsive disorder: A double blind trial of clomipramine and clorgyline. Arch Gen Psychiatry 40:605-612

Jacobs BL (1986): Single unit activity of brain monoamines. containing neurons in freely moving animals. Ann $\mathrm{N}$ r Acad Sci 473:70-77

Limberger N, Dicher R, Starke K (1991): Species differences in presynaptic serotonin autoreceptors: Mainly $5-\mathrm{HT}_{1 B}$ but possibly in addition 5-HT 11 in the rat, $5-\mathrm{HT}_{1 \mathrm{D}}$ in the rabbit and guinea pig brain cortex. Naunyn-Schmiedeberg's Arch Pharmacol 343:353-364

Maura G, Thellung S, Andrioli G, Ruelle A, Raiteri M (1943) Release-regulating serotonin $5-\left(-\Gamma_{11}\right.$ autoreceptors in human cerebral cortex. I Veurochem 60:1179-1182

Montgomery SA, Manceaux A (1992): Fluvoxamine in the treatment of obsessive compulsive disorder. Int Clin I'sy' chopharmacology 7(Suppl 1):5 9

Montgomery SA, McIntyre A, Osterheider M, Sarteschi I', Zitterl W. Zohar J, Birkett M. Wood I (1993): A doubleblind, placebo-controlled study of fluoxetine in patients with DSM-III-R obsessive-compulsive disorder. Eur Ne'uropsychopharmacol 3:143-152

Moret C, Briley M (1990a): Modulation by drugs of the re lease of total tritium and ${ }^{3} \mathrm{H} 5$-H $\mathrm{HT}$ from rat hypothalami slices. Naunyn-Schmiedeberg's Arch Pharmacol 341: 398-403

Moret C, Briley M (1990b): Serotonin autoreceptor subsensitivity and antidepressant activity. Eur J Pharmacol 180: 351-356

Piñeyro G, Blier P, Dennis T, de Montigny C (1994): Desensitization of the neuronal 5-HT carrier following its longterm blockade. J Neurosci 14:3036-3047

Ramamoorthy S, Coll DR, Mahesh VB, Leibach FH, Melikian HE, Blakely RD, Ganapathy V (1993): Regulation of the human serotonin transporter. J Biol Chem 268: 21626-21631

Rauch SL, Jenike MA, Alpert NM, Baer L, Breiter HCR, Savage CR, Fischman AJ (1994): Regional cerebral blood flow measured during symptom provocation in obsessivecompulsive disorder using oxygen 15-labeled carbon dioxide and positron emission tomography. Arch Gen Psychiatry 51:62-70

Schmidt MJ, Fuller RW, Wong DT (1988): Fluoxetine, a highly selective serotonin reuptake inhibitor: A review of preclinical studies. Br J Psychiatry 153:40-46

Steiner M (1994): Predictors of response to paroxetine therapy in OCD. Am Psychiatr Assoc Abst 147:200

Swedo SE, Pietrini P, Leonard HL, Schapiro MB, Rettew DC, Goldberger EL, Rapoport SI, Rapoport JL, Grady CL (1992): Cerebral glucose metabolism in childhood-onset obsessive-compulsive disorder: Revisualization during pharmacotherapy. Arch Gen Psychiatry 49:690-694

Waeber C, Schoeffter P, Palacios JM, Hoyer D (1989): 5-HT $1 \mathrm{D}$ receptors in guinea pig and pigeon brain: Radioligand binding and biochemical studies. Naunyn-Schmiedeberg's Arch Pharmacol 340:479-485

Wise SP, Rapoport JL (1989): Obsessive-compulsive disorder: It is basal ganglia dysfunction. In Rapoport JL (eds), Obsessive-compulsive disorder in children and adolescents. Washington DC, American Psychiatric Press, pp $327-344$

Zohar I, Insel TR (1987): Obsessive-compulsive disorder: Psychobiological approaches to diagnosis, treatment, and pathophysiology. Biol Psychiatry 22:667-687 